\title{
PRACTICE OF STANDARD PRECAUTIONS AMONG HEALTH CARE WORKERS IN A LARGE TEACHING HOSPITAL
}

Sir,

Although Iran has expanded the preventive services through the primary health care network over the last two decades, it is facing a double burden, viz., communicable and noncommunicable diseases.[1] Iran is an endemic country for hepatitis B.[1] On the other hand, the prevalence of hepatitis $C$ in Iran is about $1 \%$, which is lower than that in other regional countries of the world.[2] In addition, HIV infection is currently on the rise in Iran.[1] In this context, the implementation of standard precautions (Ups) must be widely promoted for health care workers (HCWs) who are frequently exposed to blood-borne infections. 
In order to investigate the professionals' adherence to measures of standard precautions, we conducted a study at the 550-bed Imam Reza Teaching Hospital, Kermanshah, in September 2007. A total of 120 health care workers (nurses and paramedical staff) from different departments were surveyed using a standardized questionnaire. Data were analyzed using the Epilnfo version 6 statistical package.

Within the area of assessing the use of protective devices, although the figure (94.5\%) for correct transport of safe containers was acceptable, for some others, the figures were disappointing. Use of disposable face masks whenever there was a possibility of splash or splatter was $0.0 \%$. Wearing eye shields to prevent exposure to splashing of body discharge was $6.7 \%$, with the recap of needles after injections at only $8.3 \%$. As for the use of gloves, the practice was not found to be promising; only $57.5 \%$ wore fresh gloves for the next patient, and $65.6 \%$ wore gloves when they were exposed to deep body fluid or blood product. The respondents' practice regarding the other measures were far from ideal, with the disposal of sharps coming at $74.3 \%$ and the safe method for breaking the vials accounting for $73.2 \%$. Only in $78.4 \%$ of the cases, the heavily bloodstained materials were packed in plastic bags irrespective of patients' infectious status. Covering one's own wounds or lesions in waterproof dressing before providing care to patients was at $85.5 \%$. The figures for use of standard measures after needling, washing hands after providing care to patients, and washing hands after removing the gloves were $85.6 \%, 58.2 \%$, and $31.5 \%$ respectively. Among the last figures were for decontamination of surfaces and devices at $86.3 \%$, cleaning up of blood spills immediately by using disinfectant at $74.7 \%$, and wearing a gown/apron when soiling with blood or deep fluid at a likely $67.1 \%$.

In line with some other reports from Iran and other developing countries, ${ }^{[3-5]}$ the compliance of HCWs with regard to the standard precautions was less than optimal. The partial practice of such measures in the Iranian health system contributes to the exposure of HCWs to the risk of blood-borne infections. Although we did not investigate the reasons for the prevalence of the observed figures, it might be due to different factors ranging from lack of information to lack of necessary facilities available in different wards. In developing countries where there is insufficient funding for health care resources, practicing standard precautions is much more cost-effective as compared to laboratory tests for diagnosis of patients infected with bloodborne diseases. Future studies are needed to investigate the training of personnel with regard to such measures and to see if the protective barriers are readily available.

\section{SIAVASH VAZIRI, FARID NAJAFI, FARZANEH} MIRI, FERESHTEH JALALVANDI, AFSHIN ALMASI

Department of Infectious Diseases and Tropical Medicine, Kermanshah University of Medical Sciences, Kermanshah, Iran

Correspondence: Dr. Siavash Vaziri
Department of Infectious Diseases and Tropical Medicine,
Imam Reza Hospital,
Kermanshah University of Medical Sciences, PO Box:6714415333, Kermanshah, Iran
Pons E-mail: vaziri15@yahoo.com

\section{REFERENCES}

1. Malekzadeh R. Viral hepatitis. In: Azizi F, Janghorbani M, Hatami H, editors. Epidemiology and control of common disorders in Iran. Tehran: Eshtyagh; 2001. p. 717-8

2. Alavian $S M$, Adibi $P$, Zali MR. Hepatitis $C$ virus in Iran: Epidemiology of an emerging infection. Arch Iran Med 2005;8:84-90.

3. Motamed N, BabaMahmodi F, Khalilian A Peykanheirati M, Nozari M. Knowledge and practices of health care workers and medica students towards universal precaustions in hospitals in Mazandaran Province. East Mediterr Health J 2006;12:653-61.

4. Miceli M, Herrera F, Temporiti E, Li D, Vila A, Bonvehi P. Adherence to an occupational blood borne pathogens exposure management program among healthcare workers and other gorups at risk in Argentiana. Braz $\mathrm{J}$ Infect Dis 2005;9:454-8.

5. Kermode M, Jolley D, Langkham B, Thomas MS, Holmes W, Gifford SM. Compliance with Universal-Standard Precautions among health care workers in rural north India. Am J Infect Control 2005;33:27-33. 